\title{
La consulta indígena en la institucionalidad ambiental de Chile: Consecuencias para la minería y las comunidades indígenas Collas de la Región de Atacama*
}

\author{
Indigenous Community Consultation in the Environmental Institutionality in Chile: the Consequences \\ for Mining and for the Collas indigenous communities in the Atacama Region
}

\section{Jessica Aracelí Barría Meneses ${ }^{\mathrm{a}}$}

\section{Historial del artículo}

Recibido:

5 de junio de 2019.

Aceptado:

17 de julio de 2019. a Cedrem Consultores, Santiago de Chile. Correo electrónico: jessica.barria@cedrem.cl

* Investigación elaborada en el marco de un estudio de Tesis para optar al grado M.Sc. Governance of Risk and Resources de la Universidad de Heildelberg

\section{Palabras clave}

Comunidades indígenas Collas, consulta indígena, gobernanza ambiental, gobernanza colaborativa, proyectos mineros

\section{Keywords}

Collaborative governance, Collas indigenous community, environmental governance, indigenous consultation, mining projects

\section{Resumen}

Este trabajo analiza la gobernanza ambiental aplicada al proceso de consulta indígena implementada en el sistema de evaluación de impacto ambiental (SEIA) en Chile. Las consecuencias de la inclusión del Convenio 169 de la Organización Internacional del Trabajo (OIT) sobre Pueblos Indígenas y Tribales en el EIA se evalúan a través de varios estudios de caso de interacción entre la industria minera y las comunidades indígenas Colla en Atacama. Se han analizado modelos alternativos de gobernanza de la evaluación de impacto a través de análisis cuantitativos, entrevistas exploratorias y revisión de documentos judiciales y ambientales, que incluyeron procesos colaborativos y flexibles para la solución de problemas comunes entre las partes interesadas. El análisis describe el proceso que ha llevado a la judicialización de proyectos de inversión mineros por parte de las comunidades indígenas entre 2008 y 2018. Los resultados revelan un proceso consultivo con objetivos poco claros falta de transparencia y diseño centralizado sin considerar las características culturales, temporales y lingüísticas de las comunidades indígenas. El proceso de consulta tiene limitaciones estructurales y de recursos. Esta última se asocia principalmente a restricciones presupuestarias y a una menor participación de los profesionales en el proceso de evaluación. Las limitaciones estructurales se expresan a través de diferencias comunicacionales, políticas y conceptuales entre las partes interesadas. Estas diferencias actúan como barreras que impiden un rol eficiente del Estado de Chile con las empresas privadas y las comunidades indígenas, aumentando la incertidumbre de los inversionistas privados y aumentando la desconfianza histórica hacia las comunidades indígenas.

\begin{abstract}
This work considers environmental governance concepts applied to the indigenous consultation process in the Chilean environmental evaluation system (SEIA). The consequences of the inclusion of the Indigenous and Tribal Peoples Convention (International Labour Organizatio-ILO 169) to the EIA are evaluated through several case studies of interaction between mining industry and the Colla indigenous communities in Atacama. Alternative impact evaluation governance models have been analyzed through quantitative analysis, exploratory interviews and revision of judicial and environmental documents, which included collaborative and flexible processes to the solution of common problems between stakeholders. The analysis describes the process that has led to the indictment of mining investment projects by Indigenous communities between 2008-2018. The results unveil a consultative process with unclear goals, lack of transparency, and centrally designed, without considering cultural, temporal, and linguistically characteristics of the Indigenous communities. The consultation process has structural and resource limitations. The latter is associated principally to budget restrictions and minor participation of professionals in the evaluation process. The structural limitations are expressed through communicational, political, and conceptual differences between stakeholders. These differences act as barriers that prevent an efficient role of the state of Chile with private companies and Indigenous communities, increasing the uncertainty of private investors and increasing the historical distrust of the Indigenous communities.
\end{abstract}




\section{Introducción}

En Chile a comienzos de la década de 1990- de regreso a la democracia-se reveló la preocupación por el medio ambiente, reconociéndose que el esfuerzo para lograr el bienestar económico había comprometido la conservación de sus riquezas naturales (Huencho, 2016) generando contaminación y el descontento en la sociedad civil y en los pueblos indígenas. El énfasis en el desarrollo económico generó un deterioro ambiental que debía tener una respuesta desde el estado acorde con las políticas de desarrollo con equidad y de contención social; así como acorde con los estándares internacionales (Cleary, 2007). Con el propósito por establecer los equilibrios necesarios se crea en junio de 1990 la institucionalidad ambiental representada por la Comisión Nacional del Medio Ambiente (CONAMA); y luego, el desarrollo de una política de gestión ambiental, la cual plantea la protección ambiental no como un obstáculo frente al desarrollo, sino como uno de sus elementos (CONAMA, 1994; MMA, 2016). La institucionalidad ambiental hizo crisis al entrar en contradicción los intereses indígenas con los del Estado, como fue el emblemático caso de la Central Hidroeléctrica Ralco en territorio Pewenche (Pairican, 2017; PalominoSchalscha, 2015). En este escenario, los pueblos indígenas no ajenos a esta situación comienzan a reaccionar a lo que consideran impactos del desarrollo sobre sus formas de vida, a la naturaleza y su economía de subsistencia, cimentando los conflictos socioambientales en el marco de una nueva institucionalidad (Cleary, 2007).

Debido a compromisos internacionales, la protección del medio ambiente y de los pueblos indígenas fueron temas centrales frente al ansiado desarrollo, proclamando en 1993 la Ley $N^{\circ}$ 19.253- Ley Indígena- que en el artículo $1^{\circ}$ inciso $3^{\circ}$, establece la protección indígena; y en 1994 la Ley $N^{\circ} 19.300$ sobre Bases Generales del Medio Ambiente- LBMA-. Sin embargo, ambas leyes no se vinculaban, la protección del medio ambiente y de los pueblos indígenas operaban por vías paralelas ante la falta de una mirada integral del territorio. No es hasta el año 2008 cuando Chile ratifica el Convenio $\mathrm{N}^{\circ}$ 169 sobre pueblos indígenas y tribales (DS $\mathrm{N}^{\circ} 236 \mathrm{del}$ año 2008, y vigente desde el 15 de septiembre de 2009). El Convenio 169 de la Organización Internacional del Trabajo (OIT) establece la protección de los pueblos indígenas ante potenciales efectos al medio ambiente a causa del desarrollo económico- artículo $7 \mathrm{~N}^{\circ} 3$ y $\mathrm{N}^{\circ} 4$ (OIT, 1989) -, así como también el derecho a participar por medio de una consulta indígena. En el año 2010 se modifica la LBMA con la Ley $\mathrm{N}^{\circ} 20.417$ la cual en su artículo $4^{\circ}$ inciso $2^{\circ}$ incorpora a los pueblos indígenas, y en su Reglamento N40/2012 artículo 85 del Sistema de Evaluación de Impacto Ambiental- RSEIA- regula el proceso de consulta indígena- PCI- en la normativa ambiental según el delineamiento del artículo $6 \mathrm{~N}^{\circ} 1$ letra a) y $\mathrm{N}^{\circ} 2$ del Convenio 169 , generando la vinculación de ambas leyes en términos socioambientales.

Luego de la reforma del 2010, se establece la nueva Institucionalidad Ambiental que creó el Servicio de Evaluación Ambiental- SEA- que administra al Sistema de Evaluación de Impacto Ambiental- SEIA- y que supone integrar en su procedimiento el deber de consultar a los pueblos indígenas cada vez que se prevea susceptibilidad de afectación directa por medio del PCI.

Si bien, la Ley indígena y la LBMA han sido herramientas usadas para revertir las vulneraciones económicas y culturales de nuestros pueblos originarios, ambas leyes han sido incapaces de abordar el derecho a decidir; siendo uno de los principales temas pendientes que influyen en el conflicto actual y debate sobre el reconocimiento constitucional (Donoso \& Palacios, 2018; Pairican, 2017). Bajo la teoría de participación social, Chile ratifica el Convenio 169 incorporando el PCI en las interacciones de interdependencia de un recurso cada vez que haya evidencia de susceptibilidad de afectación directa a Grupos Humanos Pertenecientes a los Pueblos Indígenas- GHPPI-, lo cual reformula la posición de los pueblos indígenas dentro de la institucionalidad ambiental (Leppe, 2015). No obstante, se han evidenciado problemas estructurales tales como: falta de una definición pormenorizada de los aspectos a consultar y de su determinación de procedencia y aplicabilidad; de los actores y sus roles; $y$ de los beneficios que se obtienen con la consulta. El proceso implementado por el Estado carece de horizontalidad en la toma de decisiones dada las barreras políticas, de comunicación y de conceptos, causando fallas bajo la teoría de la gobernanza.

Esto ha forjado una fuerte tensión entre los actores por la falta de un criterio de uniformidad teórica y práctica, así como también ante una marcada inequidad en la distribución de poder en la toma de decisiones ambientales, asimetría de información y de recursos que profundiza la desconfianza histórica de las comunidades indígenas hacia el estado y las empresas como titulares de proyectos de inversión.

La implementación de PCI tiene un impacto directo y relevante en las empresas, generando un ambiente de incertidumbre ante la inversión (Sociedad de Fomento Fabril [SOFOFA], 2016). Los cambios regulatorios que se están modelando en el país, como es PCI en el SEA, toman fuerza al momento de decidir en la inversión en un territorio, ya que de ella depende los tiempos de tramitación para obtener la aprobación, como también 
la incertidumbre asociada a una eventual impugnación y judicialización ya sea por falta de la consulta o por no ajustarse a los principios consagrados en el Convenio 169 y/o al procedimiento en la normativa ambiental vigente (Cordero, 2012; Donoso, 2014; INDH, 2014; MMA, 2016, SOFOFA, 2016).

A partir de estos antecedentes el análisis se focaliza en el PCI implementado y las fallas observadas bajo la teoría de la gobernanza, que han conducido a la judicialización de los proyectos desde 2008 al 2018, enfocando el análisis del problema en la Región de Atacama, lugar que registra el mayor número de $\mathrm{PCI}$ al pueblo indígena Colla (SEA, 2018). Por ello, el alcance de la investigación fue identificar y estudiar las causas de proyectos de inversión asociado a la minería- motor de crecimiento de la economía nacional y local (Pereira et al., 2009; Rehner \& Vergara, 2014; SOFOFA, 2016)- que han terminado judicializados desde la entrada en vigencia del Convenio 169 y su respectiva consulta. Asimismo, indagó en el proceso de gobernanza colaborativa previo al inicio de la consulta regulada, como alternativas informales de participación indígena productos de las trabas evidenciadas en el PCI. Si bien el territorio indígena y el derecho a la autodeterminación son temáticas que están en el desarrollo del trabajo, éstas no fueron abordadas dada la complejidad del tema.

Como objetivo general se analizan las consecuencias que ha generado la inclusión de la consulta indígena en el SEIA para la minería y las comunidades indígenas Collas de la Región de Atacama.
Ante ello surge la inquietud de ¿Cómo responde el mecanismo de consulta indígena a las demandas socioambientales de las comunidades indígenas?

\section{Materiales y métodos}

El cumplimiento del objetivo planteado fue gestado sobre la base del análisis de la literatura existente respecto a la teoría de gobernanza y sus derivaciones, y al Convenio 169 en función de los conceptos planteados en términos de participación. Todo aquello complementado con la revisión de la legislación ambiental en Chile y la Ley Indígena que interactúan con estos conceptos, y que luego materializó la consulta indígena en el SEA.

El análisis teórico y empírico del tema de investigación fue ejecutado en tres fases. La primera fase en gabinete, orientada a la revisión bibliográfica para fundamentar la problemática con una base teórica para luego diseñar las entrevistas. La segunda fase, correspondió a la selección del área de estudio y de los actores claves, elaboración de preguntas y al trabajo empírico de ejecución de entrevistas, la cual incluyó una visita a Copiapó para entrevistar a la Comunidad indígena Colla de Pastos Grande y Pai Ote. La última fase de gabinete consideró el procesamiento de los datos y del análisis de las entrevistas, elaboración de resultados y escritura final del trabajo (Figura 1).

De la revisión bibliográfica realizada fue necesario seguir los siguientes pasos metodológicos triangulando los datos obtenidos en:

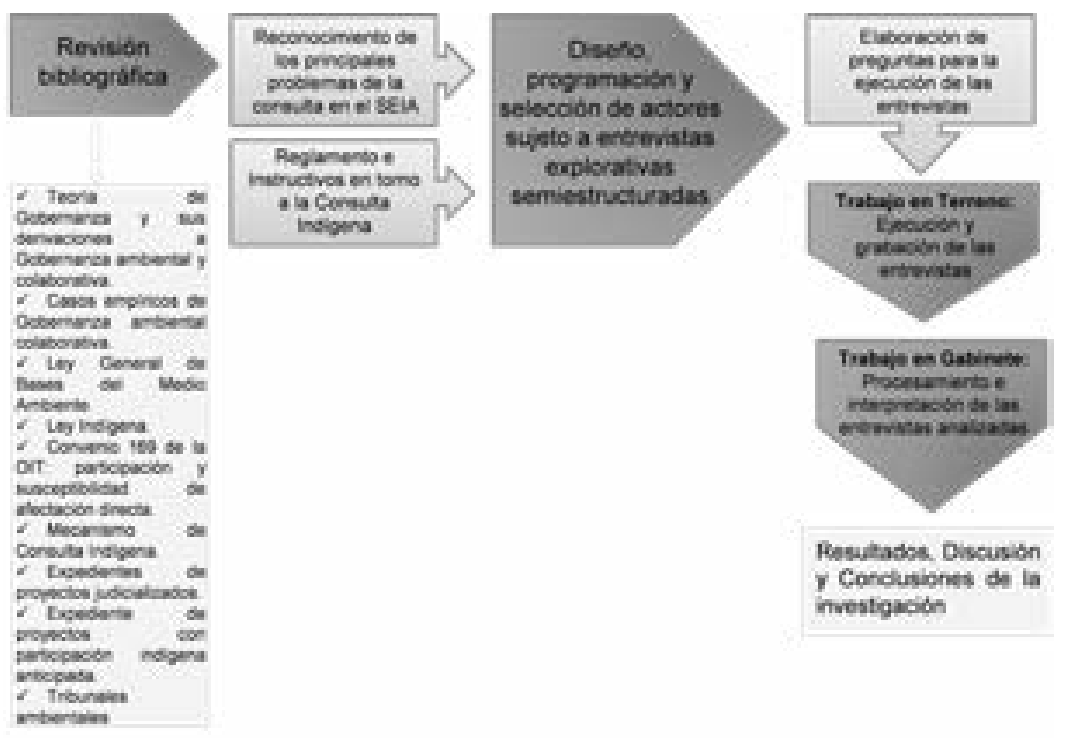

Figura 1. Esquema del proceso metodológico. Fuente: Elaboración propia. 
a. Gestión por Portal de Transparencia de todos los proyectos con PCI en el marco del Convenio 169, los cuales fueron otorgados según folio AW004T0003322 (SEA, 2019);

b. Gestión por Portal de Transparencia de todas las comunidades Collas constituidas bajo la Ley Indígena, los cuales fueron otorgados según Carta N³46/2019 (CONADI, 2019);

c. Revisión de los casos con PCI judicializados en plataformas del: poder judicial www.pjud.cl/consultaunificada-de-causas; del tribunal ambiental www. tribunalambiental.cl/; y del Sistema Nacional de Fiscalización Ambiental http://snifa.sma.gob.cl/v2/.

d. Revisión del expediente del SEIA -e- SEA-, el cual consiste en una fuente de información secundaria, de carácter público, y que resume todas las acciones y etapas del proceso de tramitación ambiental de un proyecto, tales como el EIA, DIA, ICSARA, Adendas, y RCA (EIA: Estudio de Impacto Ambiental; DIA: Declaración de Impacto Ambiental; ICSARA: Informe de Aclaraciones, Rectificaciones y/o Ampliaciones; ADENDA: Documento que concentra las respuestas a las observaciones realizadas por los servicios públicos y las comunidades a proyectos de inversión en el marco de la evaluación de un EIA).

Luego de la recopilación de antecedentes indicados, se confeccionó una base de datos con la siguiente información: año, nombre del proyecto, titular, fecha de ingreso del estudio al SEIA, comunidad indígena consultada, fecha de inicio y termino de la consulta indígena gestada, estado de proceso de consulta y resolución del PCI. Los datos aportados por esta base de datos permitieron identificar en primer lugar la evolución de los proyectos de inversión; en segundo lugar, el tiempo que dura el proceso de consulta, para poder establecer una relación entre el tiempo transcurrido y la obtención de una RCA; finalmente, identificar los proyectos que van a juicio.

En una segunda etapa del proceso metodológico, se elaboró una base de datos con la espacialización de los proyectos asociados a la minería entre 1992 - 2019 y la ubicación de las comunidades Colla en la región de Atacama. Luego de la construcción de esta base de datos, se llevó a cabo el proceso de geomática a través de la herramienta ArcGIS 10.3. Este proceso es la transformación de una descripción de una ubicación en un punto en la superficie terrestre, es decir es la expresión espacial por medio de un punto u otro elemento en la cartografía. Esta georeferenciación permitió identificar los lugares donde el desarrollo minero está generando presión sobre el medio ambiente y territorialidad de las comunidades Collas. Dado el método cualitativo usado y con el propósito de obtener distintos puntos de vista sobre la teoría de gobernanza ambiental, y de cómo ha sido ejecutado e implementado el PCI como un mecanismo de participación en la toma de decisiones ambientales; la investigación incorporó entrevistas explorativas semiestructuras a los actores relevantes que participan del proceso, los cuales fueron seleccionados en base a su experiencia y rol en torno a la consulta indígena en el SEIA. Fueron ocho las entrevistas exploratorias realizadas- todas con consentimiento previo de uso y posterior divulgación. Los actores entrevistados representan a los titulares de proyectos, asesores independientes, y al Estado a través de un representante del SEA y de CONADI. Asimismo, fueron entrevistados un representante de la comunidad Colla Pastos Grandes, comunidades Colla de Copiapó y de Pai Ote.

Para una correcta recopilación de información, las entrevistas fueron grabadas, previo consentimiento de la(os) entrevistada(os). Cada entrevista tuvo una duración máxima de 70 minutos, las cuales posteriormente fueron transcritas.

Finalmente, luego de la transcripción se utilizó la clasificación de Moore (1989) citado por Walter (2009), para estructurar los resultados en base al origen del problema evidenciado cuyos pilares fueron: información (asimetría y falta de comunicación), relaciones (desconfianza por falta de credibilidad histórica en la toma de decisiones), intereses (disputas por desigualdad en la distribución de poder y de recursos), valores (disímil valoración de un recurso ante las creencias) y estructural (instituciones formales con límites de competencia que hacen que sean incapaces de resolver las demandas de los actores).

\section{Área de Estudio}

La Región de Atacama se emplaza entre los $25^{\circ} 17^{\prime} \mathrm{y}$ $29^{\circ} 30^{\prime}$ latitud sur y desde $68^{\circ} 17^{\prime}$ ' longitud oeste hasta el Océano. Su capital es Copiapó y fue seleccionada como ejemplo de una región y ciudad claramente vinculada al auge de los commodities, específicamente a la minería de cobre (Rehnner \& Vergara, 2014). Así como también por albergar al pueblo indígena Colla desde mediados del siglo XIX en territorio de quebradas de la Cordillera de Domeyko y la puna de Copiapó (Gleisner \& Montt, 2014; Molina, 2014; Rivera, 2017) (Figura 2).

Los Collas, indígenas trashumantes, han sido vulnerados históricamente producto del abandono estatal y del desplazamiento de sus territorios a causa de la minería 


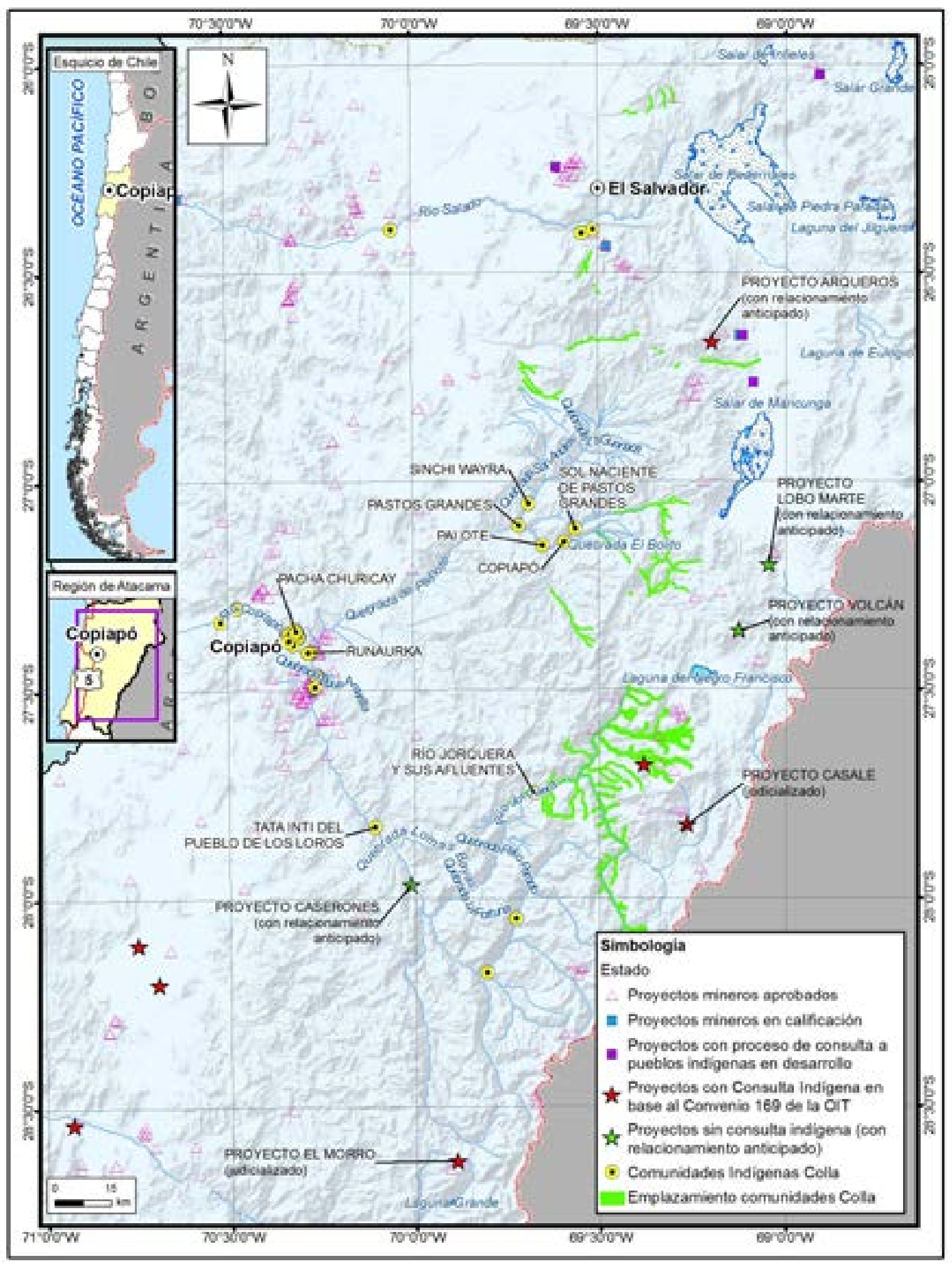

Figura 2. Área de ubicación de las comunidades indígenas collas y proyectos de inversión asociados a la minería. Fuente: Elaboración propia en base a e-SEA (2019), SEA (2019) y CONADI (2019). 
durante casi todo el siglo XX (Molina, 2014, Rivera, 2017; Universidad de Concepción, 1993).

En el transcurso de la década de 1990 comienzan los procesos de recomposición para rescatar la historia e identidad Colla y así reconocerlos política y socialmente como un pueblo indígena en el marco de la Ley Indígena (Art. $1^{\circ}$ Inciso $2^{\circ}$ ). Efecto de dicha ley, fue lograr el reconocimiento de algunas de las tierras ancestrales, donde las familias Collas se unieron y conformaron comunidades con representantes legítimos. Las primeras comunidades constituidas en virtud de la Ley fueron: Comunidad Indígena Colla Comuna de Copiapó en 1995, Sinchi Wayra en 1998 y Pastos Grandes en 1998 (Rivera, 2017). Al 2019 existe un registro de 47 comunidades indígenas Collas debidamente reconocida a través de la Ley Indígena (CONADI, 2019).

Las actuales áreas de ocupación de las comunidades Collas, coinciden- algunas de ellas- con las de la minería en términos de proyectos y/o servidumbre minera. Dichas áreas son utilizadas en la ganadería, arrieraje y cultivos en pequeña escala (Rivera, 2017). Para la ganadería ocupan el sistema de trashumancia que considera el uso de pisos ecológicos diferenciados por la altitud (invernadas y veranadas); y el cultivo lo desarrollan en los fondos de valles y quebradas (Figura 2). También desarrollan actividades como la pequeña minería, la recolección de leña y producción limitada de carbón (Gleisner \& Montt, 2014). A pesar de la diversidad de actividades realizadas, es la ganadería la principal y la encargada de la reproducción social, económica y cultural de los Collas (Gleisner \& Montt, 2014).

\section{Resultados}

En base a la revisión teórica y práctica del trabajo, surge la necesidad de conceptualizar lo que se entiende por gobernanza ambiental y participación indígena en el SEIA. De la gobernanza ambiental instaurada bajo una visión occidental surgen las posturas divergentes de los pueblos indígenas respecto al uso del territorio y sus recursos, lo que conlleva usualmente a conflictos con otros actores, tales como empresas y organismos gubernamentales. La participación indígena en el SEIA, vista como un espacio de articulación y negociación, tenía como expectativa visibilizar y empoderar a los pueblos indígenas en los procesos de toma de decisión respecto a proyectos de inversión, con impactos ambientales en territorios indígenas.

Sin embargo, la ejecución del PCI estructurado a nivel central, presenta limitaciones estructurales a nivel local debido a la diversidad de pueblos indígenas en Chile, los cuales establecen distintas relaciones de interdependencia con el entorno natural en el cual habitan.

\section{Gobernanza Ambiental en Chile}

La base del análisis teórico tuvo por eje la década de los 90s, época en la cual emergen las redes de gobernanzapara implementar en América Latina-, basadas en la interdependencia, la confianza y la empatía bajo la lógica de gestión de políticas públicas para resolver un problema común, generando estructuras y procesos (Kooiman, 2004; Mayntz, 1998; Peters \& Pierre, 2005). Como indica Stoker (1998) la funcionalidad de la gobernanza otorga un marco institucional, capaz de simplificar la complejidad de los procesos socioeconómicos, ayudando a la comprensión de los cambiantes procesos de un Estado.

El marco institucional donde es visible el intento de hacer operar la gobernanza ambiental en Chile ocurre en el SEA con su respectiva Consulta Indígena. Desde 1990 al 2018 en Chile se han evidenciado intentos de participación desde la llegada de la democracia, la cual vino acompañada con la creación de una institucionalidad ambiental- reformulada en 2010- nuevos ministerios, actores, leyes, reglamentos e instructivos (CONAMA, 1994; Cordero, 2012).

Por lo cual, la gobernanza ambiental como concepto y como teoría es una extensión de la gobernanza con el objetivo de incluir además de los aspectos sociopolíticos consideraciones asociadas al impacto de la sociedad sobre los ecosistemas naturales a causa del modelo económico imperante, intentado poder minimizarlos por medio de decisiones colectivas (Barkin \& Lemus, 2015; Bridge \& Perreault, 2009; de Castro et al., 2015). Entonces, como un concepto explicativo y organizador, la gobernanza ambiental adquiere importancia y popularidad, en el momento en el cual la autoridad y la legitimidad del estado nacional respecto a temas ambientales y de recursos naturales está cada vez más cuestionada (Bridge \& Perreault, 2009).

Por tal motivo, la teoría de la gobernanza ambiental se entiende como:

un conjunto de mecanismos, de prácticas e instituciones formales e informales, por medio de los cuales se produce el orden social a través del control de lo que está relacionado con el medio ambiente y los recursos naturales, asegurando que emerjan mecanismos adecuados de representación, participación y responsabilidad que conduzcan a la creación de instituciones de gobernanza ambiental (Aguilar-Støen, 2015; Aguilar-Støen et al., 2016). 
Como la gobernanza ambiental hace referencia a procesos de toma de decisión colectiva entre los actores interesados, y de ejercicio de autoridad en el ámbito de bienes públicos, en los cuales intervienen los servicios gubernamentales en sus distintos niveles e instancias de decisión; entenderemos al SEA como una de las 193 instituciones gubernamentales, que para estos efectos tiene por misión regular el proceso ambiental y el mecanismo del PCI implementado en 2010 en la LBMA.

Desde esta lógica, el SEA, tiene como meta la dirección y gestión respecto a la protección del medio ambiente, configurando el acceso, control y uso de los recursos naturales entre múltiples actores que participan en la toma de decisiones (de Castro et al., 2015). Por ello el SEA requiere de instructivos que logren identificar lo que los diferentes actores desean que se haga y, luego, examina los medios para alcanzar las metas colectivas. No obstante, el mecanismo de gobernanza presenta diferentes falencias, tales como el bajo impacto de la consulta debido a su subordinación a la evaluación de impacto ambiental, es decir, un proceso de toma de decisión con otros actores y reglas. Si bien, el PCI visibiliza las posiciones de los pueblos indígenas consultados, al ser un proceso no vinculante genera segregación en la participación debido a que sólo los grupos de acuerdo con el desarrollo de los proyectos de inversión son empoderados en todo el proceso, mientras que las posturas opositoras no tienen peso. Por lo tanto, el mecanismo no se hace cargo de la heterogeneidad dentro y entre las comunidades indígenas en un mismo territorio, ni responde a las aspiraciones de auto-determinación, ni (re-)valora el conocimiento indígena, provocando frustración y pérdida de confianza. En consecuencia, limita la negociación colectiva cimentando los conflictos sociambientales y a la vez potencia mecanismos informales como son los procesos alternativos de gobernanza.

\section{Participación indígena en el marco del Convenio 169}

El Convenio 169 es el instrumento político- normativo de escala global- que actualiza el Convenio $\mathrm{N}^{\circ} 107$ de 1957- de mayor relevancia en el ámbito internacional en materia de protección de los derechos de los pueblos indígenas y tribales. Dicho convenio ha promovido el respeto por las culturas, las formas de vida, las tradiciones y el derecho a la autodeterminación, asumiendo que los pueblos seguirán existiendo como parte de una sociedad, manteniendo su propia identidad, sus propias estructuras y sus tradiciones (OIT, 1989).

La implementación del Convenio 169 como un tratado internacional referido exclusivamente a los pueblos indígenas, fue de larga tramitación legislativa, la cual comenzó en 1991 siendo aprobado en 2008. Su aprobación generó grandes expectativas para los pueblos respecto a los beneficios que les reportaría su ratificación, además de generar una evaluación crítica entre políticos y abogados expertos en derechos humanos, respecto a las carencias del ordenamiento legal y la forma en que el Convenio 169 venía a suplirlas (Donoso, 2014; Leppe, 2015).

El fundamento legal de la protección indígena en la normativa ambiental a través del Convenio 169 son indicados en el artículo 7, $\mathrm{N}^{\circ} 3$ y N 4 . Cabe destacar, además, que los cuatro principios inspiradores del Convenio 169 son: igualdad ante la ley y no discriminación (negativa); no asimilación; discriminación positiva y participación (OIT, 1989). El último principio en relación a la LBMA normado en el artículo 7, $\mathrm{N}^{\circ} 3$ del convenio 169 es analizado en esta investigación.

El espíritu y sentido de la participación a través del PCI consiste en darles un tratamiento especial y diferenciado a los pueblos indígenas, atendiendo las razones de injusticia histórica reconocidas tanto en el ámbito internacional como nacional (casos emblemáticos: Pangue y Ralco; y debilitamiento de la CONADI), siendo esta una de las razones su adopción en Chile (Donoso, 2014). La diferenciación de las comunidades indígenas de las no indígenas en el proceso de consulta, ocurre porque las dinámicas de participación requieren de una comprensión histórica, política, social y cultural de las relaciones que manifiestan las comunidades indígenas con el medio ambiente, el territorio y su forma de concebir el desarrollo (Donoso, 2014; Walter \& Urkidi, 2015).

Bajo la lógica de gobernanza, la OIT (2006: 25) indica: "los Estados deberán asumir la responsabilidad de desarrollar, con la participación de los pueblos interesados, una acción coordinada y sistemática con miras a proteger los derechos de esos pueblos y a garantizar el respeto de su integridad". Por ello, es el más importante de los principios inspiradores del convenio 169 y ha sido erigida como núcleo y piedra angular del proceso participativo (OIT, 2009).

Dicho lo anterior, y como indica el artículo 6- $\mathrm{N}^{\circ} 1$ letra a- del Convenio 169, la obligación del Estado es consultar a los pueblos indígenas cada vez que se prevean medidas legislativas o administrativas susceptibles de afectarles directamente. Como medida administrativa para este estudio, es la dictación de una Resolución de Calificación Ambiental- RCA- para todo aquel proyecto de inversión evaluado ambientalmente (SEA, 2016). Asimismo- artículo $6 \mathrm{~N}^{\circ} 2$ - demanda el consentimiento previo e informado, 
y que sea de buena fe con la finalidad de llegar a un acuerdo (OIT, 1989).

La OIT (2009) también resalta oficial y extraoficialmente, que la implementación de la consulta es una de las cuestiones más complejas y difíciles para los Estados. Walter \& Urkidi (2015) indican que dicha regulación ratificada también por otros países en América Latina, es mal aplicada, a veces ignorada y ambigua. Dichas afirmaciones caben justo a la problemática de este estudio, donde la consulta como un mecanismo consultivo de participación bajo los estándares de un convenio global ha sido una herramienta que permite la visibilización de los pueblos por fallas de implementación a nivel nacional que luego son aplicadas a un nivel local en base a las particularidades de los distintos pueblos indígenas que habitan en el territorio.

El mecanismo de participación indígena sólo recibe críticas desde que fue implementado en la gobernanza ambiental en Chile (Quilaleo, 2018). Dentro de las críticas de mayor envergadura y que posteriormente serán presentadas, es que no aterriza a la particularidad de una comunidad local en base a su entendimiento de qué es el desarrollo, no es vinculante porque así también lo determina el Convenio 169. Por lo tanto, el desencanto de las comunidades afectadas cada vez que se pretende gestionar la aprobación de un proyecto de inversión, queda plasmado en la judicialización de los proyectos y en el hecho de reconocer su ilegitimidad ante el Estado. Por otra parte, los actores que forman parte del mecanismo de participación tienen aún expectativas muy disímiles del PCI. Según Quilaleo (2018) para los pueblos indígenas, el Convenio 169 debía ser un «dique de contención» que frenase, entre otros, los distintos megaproyectos que buscaban instalarse en territorios indígenas; para el Estado, era una suerte de «piedra en el zapato» que había servido para mejorar las deterioradas relaciones; y para los empresarios el Convenio 169 con su respectiva consulta retrasaría y encarecían sus inversiones.

\section{Judicialización y relacionamiento anticipado}

Fueron dos los procesos identificados por el actuar del/ los GHPPI de la etnia Colla: judicialización de proyectos, y el relacionamiento anticipado del sector privado con los GHPPI como una gobernanza ambiental colaborativa antes del proceso en el SEIA.

Judicialización de proyectos de inversión. El PCI es absoluto resultado de la ratificación del Convenio 169, siendo ideada por el estado a nivel central, sin la participación del sector privado y sin considerar la diversidad cultural de los pueblos indígenas ni de las actividades productivas que pudieran impactarlos a lo largo del país. Aquello ha permitido que los GHPPI sean visibilizados como sujetos de derecho internacional, dándoles una voz y una articulación efectiva ante los recursos de protección que han presentado.

Dicho esto, es que existe la judicialización de proyectos de inversión como un mecanismo de sanción, además de ser la instancia donde las sociedades democráticas canalizan sus diferencias, ahora visibilizadas por los pueblos indígenas (Donoso, 2014). Pues bien, la judicialización es precisamente el mecanismo para que los actores puedan ejercer sus derechos y defender sus intereses cuando uno de los actores vislumbra el no funcionamiento de los canales de comunicación y solución de diferencias entre actores interdependientes de un recurso.

Cabe destacar que siempre que ocurra jurisprudencia, ésta no procede contra medidas trámites. Es decir, no aplica para recursos de protección interpuestos contra la resolución de admisibilidad de un proyecto o interpuestos en pleno desarrollo de un PCI. Por lo cual, es la RCA en cuanto acto administrativo terminal que califica ambientalmente un proyecto, la que puede generar afectación de derechos fundamentales y por tanto hacer procedente un recurso de protección. Ahora bien, en el escenario actual hay resoluciones que podrían entenderse como 'medidas trámite' que sí son recurribles, pero no por medio de un recurso de protección, sino de recursos de la Ley de Bases de Procedimientos Administrativos (por ejemplo la resolución de inicio de un PCI, que podría generar indefensión en un GHPPI excluido; Comunicación personal con el Abogado Sebastián Donoso Rodríguez, 19/08/2017) como ocurrió con el proyecto Central Hidroeléctrica Neltume, que no posee una RCA debido a que el titular desistió su inversión. Pues bien, es así como el PCI es visto como una fuente de judicialización por tres razones:

- Añade una causa adicional para deducir recursos (principalmente el recurso de protección) por parte de los GHPPI.

- Las razones para recurrir se refieren a: sí el PCI se realizó o no; y a cómo se adecuó a los estándares nacionales e internacionales.

- Es un buen vehículo simplemente para oponerse a un proyecto, más allá de si la consulta se hizo o si se hizo bien, ya que no existe posibilidad que los GHPPI puedan negarse a un proyecto de inversión. 
Según Cordero (2012), la corte suprema en su rol de experto en derecho público, mira los casos asociados a la regulación ambiental, con los anteojos de la teoría del Derecho y del procedimiento administrativo para resolver conflictos ambientales. En palabras más claras, que existan conflictos no se deben únicamente a prácticas erradas o carencia de implementación de reglas, sino más bien, se debe al diseño estructural de la institucionalidad ambiental, en el cual el SEIA actúa como- una ventanilla única- un procedimiento administrativo integrado, donde no hay horizontalidad en la toma de decisiones, así como también omisión de participación.

Antes de la creación de los tribunales ambientales, la Corte Suprema en su condición de experto en derecho público, tuvo la facultad de impugnar los proyectos ingresados a evaluación, como también a las RCA cuando se evidenciaba incumplimiento del derecho público y del proceso administrativo (Cordero, 2012).

La jurisprudencia en esta materia ha sido vacilante, no obstante, el creciente reconocimiento a la consulta previa, libre e informada de naturaleza jurídica es un hecho materializado a pesar de los diferentes fallos emitidos (INDH, 2014).
En el año 2011, la Corte Suprema (Rol Nº 2211 - 2011, 27 de abril de 2012) reveló un fallo estructural en la gestión ambiental por omisión en la aplicación del Convenio 169 y su impacto dentro del SEIA(Cordero, 2012), (Tabla 1). La falla ocurre no sobre las bases de cuestiones ambientales, sino por debates enfocados en el procedimiento administrativo que vulnera los derechos fundamentales de los GHPPI en su territorio (Cordero, 2011; Cordero, 2012).

Es así como en un inicio, los PCI fueron implementados en la medida que la jurisprudencia indicaba criterios y estándares de acuerdo a los referido en el Convenio 169. Por ejemplo, en una primera época los procesos de participación ciudadana- PAC- eran suficientes para cumplir con el deber de consulta del Convenio 169 según los fallos de la corte suprema dictados entre 2008-2011 (Tabla 1), (Donoso, 2013, INDH, 2014). Luego las PAC debían ajustarse a estándares indígenas- 2011- para finalmente en 2012 con el RSEIA concretar la implementación del PCI diferenciado de la PAC (SEA, 2017).

Al no existir un procedimiento claro (Quilaleo, 2018), los juicios ocurrieron para todo tipo proyectos con distintas formas de o no ingresos al SEIA, por ejemplo, para estudios ingresados como DIA que según RSEIA no aplica el deber de consulta. Es por ello que al 2013 había un registro

Tabla 1

Proyectos mineros judicializados en la Región de Atacama por efectos de PCl.

\begin{tabular}{|c|c|c|c|}
\hline Nombre del proyecto y titular & $\begin{array}{l}\text { Monto fecha y } \\
\text { vía de ingreso }\end{array}$ & $\begin{array}{l}\text { Demanda por parte de las comunidades } \\
\text { indígenas }\end{array}$ & Fallo de la Corte Suprema \\
\hline $\begin{array}{l}\text { Estudio de Impacto } \\
\text { Ambiental Proyecto El Morro } \\
\text { / Sociedad Contractual } \\
\text { Minera El Morro }\end{array}$ & $\begin{array}{l}\text { US } \$ 2.500 \\
\text { millones } \\
25 / 11 / 2008 \mathrm{EIA}\end{array}$ & $\begin{array}{l}\text { Tres recursos de protección: Rol 143/2011; } \\
618 / 2011 \text { y } 435 / 2013 ; \text { todos aluden al } \\
\text { Convenio } 169 \text { y al no efectuarse el PCl. }\end{array}$ & $\begin{array}{l}\text { Revocó RCAResolución Exenta Nº 232/2013. "evidencia } \\
\text { de ilegalidad de la resolución que aprobó el EIA, al } \\
\text { no haber realizado consulta a las comunidades } \\
\text { recurrentes por parte de CONADI" Tres sentencias } \\
\text { de la Corte Suprema: Rol N }{ }^{\circ} 8.644 \text { del 13/12/2011; } \\
\text { Rol N }{ }^{\circ} 2211 \text { 27/04/2012; y Rol N¹1.299 07/10/2014. }\end{array}$ \\
\hline $\begin{array}{l}\text { Optimización Proyecto } \\
\text { Minero Cerro Casale / } \\
\text { Compañía Minera Casale }\end{array}$ & $\begin{array}{l}\text { US } \$ 5.200 \\
\text { millones } \\
\text { 29/07/2011 EIA }\end{array}$ & $\begin{array}{l}\text { Un recurso de protección ante la Corte de } \\
\text { Apelaciones de Copiapó en contra de la } \\
\text { aprobación de la evaluación ambiental que } \\
\text { realizó el SEA, para dejar sin efecto la RCA } \\
\text { por cuanto afectaría a las comunidades } \\
\text { indígenas Collas, las cuales no habrían sido } \\
\text { consultadas previamente de acuerdo al } \\
\text { Convenio } 169 \text {, alegando que no se ajustó } \\
\text { a derecho y que las observaciones de la } \\
\text { comunidad no fueron tomadas en cuenta. } \\
\text { RCA reclamada } 10 \text { veces, siete al PAC, } \\
\text { de esas siete una por infracción a las } \\
\text { normas del Convenio } 169 \text {, la cual no } \\
\text { fue acogida. }\end{array}$ & $\begin{array}{l}\text { No revoca la RCA Resolución Exenta 004/2013. "La } \\
\text { existencia de un procedimiento de consulta en el } \\
\text { marco del proyecto no implica la obligatoriedad } \\
\text { de la empresa de acogerlas, concluyéndose que } \\
\text { no aparece que dicha resolución haya afectado las } \\
\text { garantías invocadas por el recurrente, toda vez que } \\
\text { la igualdad ante la ley se ha respetado en forma } \\
\text { irrestricta en todas las etapas de la evaluación y por } \\
\text { todas las actuaciones de las partes evaluadoras". PAC } \\
\text { con estándar indígena reclamado, pero rechazado } \\
\text { Rol } 26-2013 \text { y } 165-2013 \text {. } \\
\text { Si una comunidad no quiere participar del PCl ésta } \\
\text { es igual de válida como proceso acorde a como fue } \\
\text { implementada en Chile, pudiendo el tribunal fallar que } \\
\text { se intentó realizar (SEIA, Comunicación personal 2017). }\end{array}$ \\
\hline
\end{tabular}

Fuente: Elaboración propia en base a e-SEIA, Corvalán (2015) y Centro de Políticas Públicas 
de 19 proyectos en juicio con distintos fallos: 10 contra RCA respecto a DIA; seis contra RCA respecto a EIA, dos contra resoluciones de la Comisión de Evaluación Ambiental (CEA); y uno contra actividades no ingresadas al SEIA (Corvalán, 2015; Donoso, 2013; PWC, 2014).

De la revisión realizada para ver la jurisprudencia en alusión al Convenio 169, al 2019 existe un total de 15 proyectos ingresados como EIA que fueron a tribunales. De los 15 casos, nueve cuentan con PCI, y seis con PAC. Para los seis casos, las comunidades indígenas demandan que sí habrá susceptibilidad de afectación directa y que por lo tanto requiere del PCI. Lo interesante a destacar de las seis reclamaciones por no aplicar el PCI, es que hay una reclamada el 13 de julio de 2018 a una RCA del 2009 (Rol 190-2018), fecha en la cual el Convenio 169 aún no entraba en vigencia en la legislación ambiental.

Para el periodo de vigencia del Convenio 169 son 51 los proyectos de inversión ingresados como EIA con PCI, de los cuales 34 están cerrados y 17 en curso (SEA, 2019). De los 34 procesos cerrados nueve $(26,5 \%)$ presentan juicio. En la región de Atacama son 12 los proyectos con PCI de los cuales siete están asociados a la minería. De estos siete, dos fueron judicializados. Empero debo indicar que el proyecto Pascua Lama sin PCI, también fue reclamado en la región por temas indígenas de etnia Diaguita en alusión al Convenio 169 (Rol 144/2017). Los dos proyectos mineros judicializados en la región de Atacama, ocurrieron en los inicios de la implementación del PCI, por lo cual, las causales hacen referencia a lo previo y al derecho ancestral, así como al proceso administrativo ante la carencia de protocolos teóricos y metodológicos claros (Cordero, 2012; Ríos \& Canessa, 2014; Corvalán, 2015; Quilaleo, 2018) (Tabla 1).

No obstante, aquello, al 2018, todos los actores entrevistados, así como también lo expresa FIMA (2016) aluden a que la judicialización de proyectos está asociado a un déficit regulatorio aún sin resolver. Es evidente la necesidad de incorporar aspectos que establece el Convenio 169 y que siguen pendientes en el proceso implementado, como es el derecho a la autodeterminación y de sus territorios, además de acoger aspectos locales entre y dentro de los pueblos indígenas $\mathrm{y}$, por otro lado, el manejo del conocimiento indígena en la toma de decisiones ambientales.

Los sucesos de judicialización, sobre todo el realizado a un proyecto con RCA del 2009, da más fuerza a la importancia de la consideración de la componente indígena en la evaluación ambiental de proyecto en los territorios donde aspiran a emplazarse. Donoso \& Palacios (2018), invita al debate sobre la necesidad del reconocimiento de los pueblos indígenas como sujetos de derecho para lograr la integridad y equidad de derechos, y tal vez así habrá certeza en las aprobaciones ambientales de proyectos de inversión. Sin duda este hecho significaría un salto cualitativo en la adaptación del marco legislativo nacional e institucional a los preceptos establecidos en el Convenio 169.

Del análisis del proceso de consulta indígena en proyectos mineros en la región de Atacama, se evidencia que no es del todo inclusiva respecto a:

- No son consultados ni participan formalmente de los estudios antes-previo- de ser ingresados al SEIA.

- No es posible saber si sus observaciones fueron incorporadas antes de la emisión de la RCA por parte del SEA.

- No existe en el proceso una etapa participativa una vez dictada la RCA.

Respecto a la forma de entender lo previo entre los actores éste difiere a lo previo desde la perspectiva indígena. Es decir, no hay participación ni incorporación de su conocimiento ni de sus tradiciones indígena en el desarrollo de un EIA; que permita diseñar, ubicar, o desarrollar las acciones del proyecto desde la perspectiva de un conocimiento integrado antes que éste sea ingresado al SEIA.

Si bien es evidente que la estructura y el proceso de consulta indígena presentan aún fallas procedimentales, desde la perspectiva de una gobernanza, como también carencia en reconocer derechos y equilibrar las interrelaciones con los actores, existe motivación para ir generando procesos de aprendizajes flexibles para resolver el problema y así poder eludir la judicialización logrando acuerdos con la comunidad, tal como indica la OIT (1989) y como lo recomienda recientemente la OIT (2016) en el reporte regional.

Sin embargo, al analizar con los actores entrevistados el PCI mejorado al 2016, todos identifican la asimetría de información, de recursos y de distribución de poder en la toma de decisión final de un proyecto de inversión, donde la teoría de gobernanza no aporta a la resolución de problemas de participación indígena. Por ejemplo, los titulares de proyectos, pese a que su rol de participación queda sujeto al acta de acuerdo metodológico (SEA, 2016) a veces puede ocurrir que no participan en el PCI, ya que como indica el Convenio 169, es el Estado el responsable de ejecutarla. Aquello conduce a que los GHPPI usan tanto al titular- empresa- como al SEIA- Estado- para lograr satisfacer sus demandas, pudiendo provocar conflictos 
de interés, ya que no todos los actores participan en el mismo proceso. Como afirma Donoso (2014) este actuar ocurre debido a que existe una compleja interacción entre lo que el Estado y las empresas hacen o dejan de hacer, que luego es demandado por las comunidades.

En consecuencia, es muy probable que los GHPPI sigan acudiendo a los recursos de protección cuando no se logren los acuerdos en el PCI, dada la nula participación e integración indígena luego de dictada una RCA, como también cuando sientan vulneración de sus derechos, o básicamente para negarse a un proyecto que no quieren en su territorio, debido a que esta última instancia de participación en Chile no existe.

\section{Relacionamiento anticipado o Gobernanza ambiental colaborativa entre comunidades indígenas y empresas. Las consecuencias positivas en este proceso- de aprendizaje por prueba y error- es que los titulares de proyectos gestan procesos anticipados de comunicación y negociación permanente con los GHPPI desde la perspectiva de la gobernanza ambiental colaborativa.}

Al ver trabado el proceso en el SEIA, que luego repercute en retardos y sobrecostos en la inversión inclusive con una RCA a favor, han aplicado otra alternativa de diálogo como es el proceso de relacionamiento anticipado con los GHPPI, no solo con el objeto de obtener un RCA, si no que saben muy bien que deben convivir permanentemente con ellos durante la vida útil de su proyecto. Por esto, además incorporan en su organigrama un área de relaciones comunitarias con presupuestos asociados desde un inicio en la planificación inicial hasta el cierre de faenas que incluye capacitaciones e inducciones constantes para ellos como también para las comunidades indígenas.

En la región existe evidencia de cuatro proyectos-Caserones, Arqueros, Lobo Marte, y el Volcán- de relacionamiento anticipado, como un proceso de gobernanza ambiental colaborativa, previo ingreso al SEA(Tabla 2). Dicho proceso emerge en respuesta a la ratificación del Convenio 169 y a los principios consagrados para las empresas miembros del Consejo Internacional de Minería y Metales (ICMM en sus siglas en inglés). Si bien, las empresas no están sujetas a obligaciones directas- deber del estado- ésta tiene evidentes consecuencias sobre la inversión (Donoso, 2014; Quilaleo, 2018), como ocurrió con la judicialización de proyectos y/o la ralentización del proceso (SOFOFA, 2016). Al respecto, existen dos visiones: 1) SOFOFA (2016) afirma: "La iniciativa demoró más de dos años tramitándose en el sistema de evaluación ambiental y desde la propia empresa explicaban que el atraso se debía al proceso de consulta" (p.12). En referencia al Proyecto RT Sulfuros (Fase II), el SEIA aprobó el EIA en enero del 2016, con PCI- Res N 222 13/08/2013- Dicho proyecto igual fue reclamado R-157-2017. 2) SEA: se responsabiliza a la consulta indígena, pero a veces el retraso del proceso ocurre porque las líneas de bases son deficientes... (Erick Wiederhold, Comunicación personal 2017).

La Tabla 2 muestra que los acuerdos no siempre se relacionan al proyecto en evaluación ambiental, sino a amparar en base a beneficios económicos a la comunidad cuando ocurra la operación del proyecto. Aquello, requiere de una reflexión mayor ante la crítica que hacen los titulares- dar lo que el estado deja de dar- y de los actores civiles cuando indican que los titulares distribuyen dinero para lograr los acuerdos. En consecuencia, el logro de acuerdos en esta gobernanza ambiental colaborativa, evidencia que el mecanismo de consulta indígena como un proceso formal implementado por el Estado no responde a las demandas socioambientales de las comunidades indígenas, dado que no fue diseñado para ello y por ende pierde legitimidad.

La vinculación temprana observada sucede en una escala local dada la incertidumbre que genera el Estado. Incorpora la integración de la visión indígena en su organización y planificación dándoles oportunidades de trabajos, asimismo en los tiempos que dura el proceso respetando las tradiciones culturales de una comunidad particular. Dispone de una buena articulación de actores con capacidades competentes para emprender el diálogo anticipado, y así ir generando vínculos estables y de largo plazo en todas las etapas que conlleva un proyecto de inversión.

En estos casos de gobernanza colaborativa, los pueblos indígenas son el actor clave- Stakeholder- no obstante, al ser un mecanismo no regulado pueden diferir entre empresas. Sin embargo, en base a los resultados de las entrevistas realizadas, todos convergen en que es una buena herramienta de articulación dado que facilita las instancias de información y participación indígena fomentando el diálogo y las negaciones posteriores dentro del PCI formal del SEIA.

Con estos resultados, y al amparo teórico sobre la idea fundamental que establece una estrategia de gobernanza ambiental como aquel "intento de los órganos rectores o sus combinaciones para aliviar los dilemas ambientales reconocidos" (Bridge \& Perreault, 2009: 478-477), es que en estas anticipaciones es fehaciente la participación del Stakeholder clave y así la posterior toma de decisión, informados y consientes de las consecuencias ambientales, económicas y sociales en el lugar que surge efecto. 
Tabla 2

Proyectos mineros con relacionamiento anticipado en la región de Atacama.

\begin{tabular}{|c|c|c|}
\hline Nombre del proyecto y titular & $\begin{array}{l}\text { Fecha y vía de } \\
\text { ingreso }\end{array}$ & Acuerdos logrados con diferentes comunidades indígenas Collas \\
\hline $\begin{array}{l}\text { Proyecto Caserones / SCM } \\
\text { Minera Lumina COPPER } \\
\text { Chil }\end{array}$ & 21/10/2008; EIA & $\begin{array}{l}\text { Modificación de } 30 \text { torres de un tendido eléctrico que afectaba vertientes y vegas utilizadas por el } \\
\text { ganado. Se definió un nuevo trazado, además que la mantención y el suministro eléctrico fuera } \\
\text { monitoreado por la comunidad y la empresa; cursos obligatorios sobre cosmovisión y cultura } \\
\text { Colla; y un programa de Desarrollo Estratégico de la Comunidad Colla con proyectos de energía } \\
\text { renovable, desarrollo agro-silvo-pecuario, desarrollo turístico y monitoreo ambiental. Todo aquello } \\
\text { firmado bajo un acta de Protocolo de Cooperación (Corvalán, 2015). }\end{array}$ \\
\hline $\begin{array}{l}\text { Reinicio y Expansión } \\
\text { Proyecto Lobo Marte/ } \\
\text { Minera Lobo Marte } \\
\text { Limitada* }^{*}\end{array}$ & 29/06/2011; EIA & $\begin{array}{l}\text { Apoyo hacia actividades culturales, desarrollo de proyectos turísticos, difusión de la cultura } \\
\text { Colla, capacitación a transportistas locales, instalación de señalética, de un equipo de primeros } \\
\text { auxilios en un lugar estratégico, de mecanismo de reclamos; reuniones mensuales entre actores, } \\
\text { capacitación para el desarrollo microempresarial (visto in situ con mi visita a terreno), apoyo de } \\
\text { alfabetización de miembros de las comunidades, cursos para operaciones de mina y planta, plan } \\
\text { de reinserción laboral, creación de una bolsa de trabajo, entrega de becas educativas anuales, } \\
\text { y otras becas técnicas (Corvalán, 2015). }\end{array}$ \\
\hline $\begin{array}{l}\text { Modificación Sondajes } \\
\text { de Prospección Proyecto } \\
\text { Volcán/Andina Minerals } \\
\text { Chile Ltda }\end{array}$ & 19/08/2011; DIA & $\begin{array}{l}\text { Mantener el diálogo con las comunidades; implementar programas de rescate patrimonial; apoyar } \\
\text { la celebración de fiestas e incorporar la perspectiva cultural en la definición o modificación de } \\
\text { los acuerdos. Asimismo, se reconocen en términos de protección del patrimonio ambiental y } \\
\text { cultural de las comunidades, la existencia de sitios de valor natural, y sitios de significación } \\
\text { arqueológica (e-SEIA, 2017). }\end{array}$ \\
\hline $\begin{array}{l}\text { Proyecto Arqueros/ Laguna } \\
\text { Resources Chile Limitada }\end{array}$ & $\begin{array}{l}\text { 29/12/2011; EIA. } \\
\text { 09/07/2018; EIA }\end{array}$ & $\begin{array}{l}\text { Se determinó en conjunto la necesidad de realizar una "consultoría independiente" al EIA, con } \\
\text { el fin de asegurar que se resguarden los recursos ambientales y patrimoniales del territorio, y } \\
\text { que a su vez se logren incorporar todos los impactos al medio ambiente detectados. Se tomaron } \\
\text { medidas asociadas a la protección del patrimonio ambiental y cultural de las comunidades (cambio } \\
\text { del trazado, posibilidad de trasladar especies vegetales a otros sectores) (e-SEIA, 2017). Con } \\
\text { el reingreso del EIA, desde octubre de } 2016 \text { han ejecutado el relacionamiento previo con el } \\
\text { propósito de incorporar, desde la etapa de diseño, medidas que respondan a las inquietudes de } \\
\text { las autoridades locales y las comunidades indígenas Collas. }\end{array}$ \\
\hline
\end{tabular}

Fuente: Elaboración propia en base SEA (2017b) y Corvalán (2015).

\section{Discusión}

Las convenciones, protocolos y tratados internacionales que Chile suscribió producto de la globalización de nuestra economía provocaron conflictos socioambientales a escala nacional, regional y local. Por otra parte, también influyeron en la modificación de la legislación nacional, con la creación de mecanismos de participación bajo el eslogan de desarrollo equitativo, inclusivo y sustentable (Cleary, 2007). No obstante, aún persisten deficiencias que requieren ser abordadas conforme mandata la legislación nacional e internacional en materias como la integración real y el equilibrio para la toma de decisiones con los pueblos indígenas.

La estructura y el proceso de la gobernanza ambiental está muy arraigado en la tradición occidental de la toma de decisiones (Zurbriggen, 2011), a pesar que permite a los GHPPI participar en el proceso de consulta, la crítica es indiscutible en tanto que las decisiones se basan en conocimientos bajo evidencia científica y económica, muy lejano a la experiencia y conocimiento tradicional y cultural de los GHPPI (Ellis, 2005; Quilaleo, 2018; von der Porten et al., 2015).

La gobernanza implementada en Chile, forma parte de un proceso flexible que ha promovido el aprendizaje, la participación indígena, como también está en un constante tira y afloja de prueba y error (Prats Català, 2005). La judicialización de proyectos, ocurre porque en la práctica, la teoría de gobernanza no hace eco, generando fallas tanto por falencias metodológicas y procedimentales, como también al hecho que al consultar a los pueblos indígenas no todas las observaciones son plasmadas en la toma de decisiones antes de emitir una RCA. Este acto conduce a que el proceso no genere garantías para los actores que son parte de las negociaciones y por otro lado excluye las posturas opositoras de un proyecto.

La teoría de la gobernanza promueve el intercambio de información y conocimiento para conformar un núcleo en la interrelación de actores (Rhodes, 1996; Stoker, 
1998). Sin embargo, la consulta indígena, como opera en Chile, no conforma este núcleo, no se satisface con la sola transmisión de información a las comunidades indígenas (INDH, 2014). Dicha evidencia debe ser una oportunidad para abrir un diálogo participativo/normativo y reducir las diferencias en torno a las demandas legítimas de los pueblos que actualmente no se están cumpliendo a cabalidad. Para ello, se debe aterrizar aún más la práctica de una gobernanza hibrida entre la ambiental y la colaborativa, con soluciones locales en base a las particularidades de cada GHPPI (Barkin \& Lemus, 2015; Bingham, 2009; Bridge \& Perreault, 2009; Moore et al., 2017).

Las empresas mineras consultadas buscan informar a las comunidades indígenas sobre sus proyectos de inversión ya que reconocen la existencia de asimetrías de información y de recursos en el PCI. Por eso, además aproximan el entender del comportamiento y conocimiento indígena en su estructura interna, y con ello trabajan en la búsqueda de una solución para que un proyecto sea viable ambiental y socialmente. Sin embargo, es importante mencionar que además existen otros mecanismos de obligación para la inclusión indígena como el ser parte del ICMM y ser financiados por el IFC, que en ambos casos buscan proteger los intereses los pueblos indígenas consagrados en los principios del ICMM como también a los asociados al Convenio 169 con su respectiva consulta indígena.

Uno de los alcances fue indagar en las causas de judicialización de proyectos, considerando como hallazgo de este trabajo es que la asimetría de información y la falta de transparencia provienen del estado- actor clave en la gobernanza-. La facilitación para acceder y comprender los aspectos técnicos de los estudios no es otorgada por el estado, lo que genera y seguirá generando la desconfianza de los pueblos indígenas hacia ellos. Asimismo, por parte de las empresas, se percibe falta de información de cómo se está llevando a cabo el PCI en el SEIA, la interacción del estado con la empresa también es deficiente. Por lo tanto, el Estado, quien intenta fomentar la gobernanza no logra generar certidumbre ni confianza en el PCI.

De acuerdo a los actores entrevistados todos convergen en que la deuda histórica con los pueblos aún está latente, y que no ha sido resuelta con la incorporación de la consulta indígena en base a los estándares del Convenio 169. Por ello, desde la perspectiva de la gobernanza, como un proceso flexible, que reconoce las características de los actores, en como ellos ven el problema y poder dar solución a éste, es que la consulta indígena requiere ser ajustada a la realidad nacional y luego local de donde surge. Aquello debido a que la escala del problema es distinta a la escala de la solución (Jessop, 1998). Asimismo, requiere reafirmar la identidad indígena, el derecho político a la autodeterminación, al territorio y al saber (Ellis, 2005). Una inyección de recursos económicos para la generación de espacios de autonomía para las comunidades indígenas, podría nivelar las relaciones de poder y de conocimiento en todo el proceso, facilitando la posterior toma de decisiones en la gobernanza (von der Porten et al., 2015).

Palomino-Schalscha (2015), indica que un devenir para defender, validar diferencias, legitimar y expandir roles de nuestros indígenas como actores políticos no ocurriría únicamente por los derechos otorgados por el estado, y así lo demuestra con el caso de Trekaleyin. Si bien, no es el único mecanismo para lograr desde la perspectiva de gobernanza una determinación a la hora de decidir sobre la solución de una problemática. Si sería de utilidad que el estado otorgue el reconocimiento de sujetos de derecho nacional e internacional, y reconocer la plurinacionalidad en la constitución chilena, ya que vemos que tanto la Ley Indígena como la LBMA no han sido suficiente para responder las demandas socioambientales de las comunidades indígenas que son consultadas en los proyectos de inversión.

Este reconocimiento podría acercar posturas divergentes y así dar participación e inclusión con una reestructuración del proceso e inclusive de las instituciones del estado con competencia ambiental y social para resolver un problema histórico y común desde la perspectiva de gobernanza (Jessop, 1998; Stoker 1998). Empero, las comunidades deben ser más que un stakeholder, deben ser un actor cuyo derecho inherente a la autodeterminación sea un hecho (von der Porten et al., 2015, Moore et al., 2017). Actualmente las sociedades civiles y los pueblos indígenas no tienen un poder decisorio sino más bien el estado otorga la capacidad para proponer, argumentar, experimentar y denunciar.

Los instrumentos de gestión ambiental, en el ámbito de los derechos de los pueblos indígenas deben considerar no sólo la ordenación y protección del medio ambiente, sino satisfacer y orientarse a garantizar los derechos colectivos, incluido el de decidir sobre el uso y goce de los recursos naturales en su territorio (INDH, 2014; Walter y Urkidi, 2015; Moore et al., 2017; Donoso y Palacios, 2018; Quilaleo, 2018).

La inclusión social y ambiental en los EIA debe ir más allá de la ambientalización del problema, siendo necesaria la incorporación pormenorizada de los impactos directos e indirectos sobre la afectación de derechos indígenas en sus 
formas de vida y en su interacción con la naturaleza más allá del uso en aquellos extensos territorios donde ocurre su existencia y subsistencia. Con esto, el modelo teórico de gobernanza ambiental colaborativa, revela un profundo desafío de reestructuración del mecanismo de consulta y más aún si se traslada o crea otra institucionalidad con competencias sociales y ambientales.

La compleja relación de interdependencia de los recursos naturales entre actores, en base al modelo teórico propuesto, podría responder a las demandas de nuestros pueblos respecto al derecho ancestral del territorio y de ser naciones auto determinantes, ya que en la actualidad quedan totalmente fuera de la estructura del SEA y del PCI. Además, dicho modelo generaría oportunidades efectivas de participación en la toma de decisiones por parte de los pueblos indígenas y en este caso de estudio, de los Collas trashumantes que se niegan a participar del PCI. Dicho esto, la participación no sería por fuera del proceso, sino que sería efectiva con los representantes del estado y con los titulares de proyectos.

En palabras de Gómez Muñoz (2003), uno de los grandes desafíos socioambientales en los territorios indígenas, es lograr el respeto e incorporar los saberes indígenas en las tomas de decisiones ambientales con un carácter interdisciplinario. Además, Leff (2003) menciona otro desafío como el construir un saber ambiental desde los saberes tradicionales, conviviendo, aprendiendo y compartiendo los conocimientos indígena y no indígena en todos los tipos y niveles de interrelaciones espaciales y temporales. Estos grandes desafíos requieren de voluntad política, pudiendo ser efectivos al reconocer a los pueblos indígenas en la constitución.

La experiencia indica que en base a los hechos el aprendizaje puede transformarse en aprender haciendo juntos estrategias de participaciones previas e inclusivas (Gómez-Muñoz, 2003; Moore et al., 2017) para mejorar las relaciones entre todos los actores, especialmente con el Estado, que es quién debe aprender de sus errores históricos y de deudas con los pueblos indígenas. Mientras tanto las comunidades indígenas siguen cultivando la paciencia y la espera. Muestra de ello, es que, en la complejidad ambiental de la región de Atacama, los Collas son visibles por todos los actores de nuestra sociedad a partir del año 2013.

\section{Conclusiones}

La consulta indígena en la institucionalidad ambiental ha tenido como consecuencia para la minería de la región de Atacama la paralización de algunos proyectos, lo que generó una baja en la inversión local durante el periodo 2013-2015 (SOFOFA, 2016). Por otro lado, las comunidades indígenas Collas son ahora visibilizadas por su actuar tanto por la presentación de recursos de protección como también por su participación en una gobernanza colaborativa con los inversionistas de la región.

Las comunidades indígenas Collas se niegan al proceso de participación en torno a la consulta indígena ya que no la consideran legítima dado que ésta no se hace cargo de la heterogeneidad dentro y entre las comunidades indígenas en un mismo territorio y no responde a las aspiraciones de auto-determinación ni de revaloración indígena que esperaban al ratificarse el Convenio 169. La desconfianza hacia el Estado sigue latente, sin embargo, sorprende las relaciones anticipadas y de buena fe que han realizado directamente con las empresas mineras, quienes escuchan sus demandas, generando trabajo inclusivo en etapas previas. El Estado para ellos sigue ausente, ya que sólo se presenta para informarles de un proyecto, que ellos ya conocen por otras fuentes.

La minería al ver un Estado débil, y al ver las necesidades y lograr entender los intereses de una comunidad indígena, anticipa el proceso de diálogo y negociación. Como parte de la política empresarial han implementado un área de relacionamiento comunitario donde el eje principal es el relacionamiento temprano con las comunidades. Este actuar toma fuerza como parte elemental del organigrama empresarial, así como también en la planificación de los proyectos.

El Estado, al entender la gobernanza como un aprendizaje, sigue buscando el mecanismo adecuado para incentivar la inversión, y mejorar las relaciones de interdependencia con los GHPPI. Sin embargo, sigue sin entender que para que el proceso de gobernanza surja efecto debe haber horizontalidad en la toma de decisiones, en las relaciones de poder y transparencia/simetría en la información.

La consulta indígena implementada requiere de una inversión importante en términos de recursos y profesionales para luego capacitar e implementar acorde a la realidad indígena. Debe haber una mayor consideración en los presupuestos ministeriales para estos efectos, debido a que es una falencia significativa para acceder al territorio donde emerge un conflicto que está sujeto a consulta indígena. Si bien, se han generado pautas metodológicas para facilitar el proceso de consulta indígena en el SEA, no hay certeza si esto mermará la judicialización de proyectos, ya que ésta sigue sin resolver los problemas de fondo como es el asentado en el principio de autodeterminación indígena 
que está consolidado en el Convenio 169 y que ha sido expresamente recogido por la jurisprudencia internacional. En base al principio de participación de acuerdo al Convenio 169 y su incorporación al SEA, es urgente generar una política nacional donde los pueblos indígenas participen en todo el proceso, para definir bajo una lógica lo que entenderemos por territorio, ya que desde este concepto surgen los problemas cuando hay que aplicar o no una consulta referida a la susceptibilidad de afectación directa que dicta la Ley ambiental.

El concepto de territorio indígena señalado por el Convenio 169 , es escasamente recogido por la normativa interna que regula la tenencia de la tierra de carácter indígena. Por ello, es necesario el llamado a investigar sobre las consecuencias ante la divergencia conceptual que existe y que influyen no solo en aspectos de competencia ambiental si no también políticas. Asimismo, urge tener una planificación territorial del país, que logre dar claridad donde desarrollar un proyecto de inversión en armonía y en relación con sus habitantes, sean indígenas o no indígenas. Los ejemplos de negociación anticipada como una gobernanza participativa y colaborativa producen efecto cuando el territorio a intervenir corresponde a áreas indígenas. La colaboración de los indígenas Collas, es real. Ellos quieren el progreso de Chile y de su región, no se niegan a eso. Ellos piden trabajo y que no sigan vulnerando sus derechos. Creen más en los titulares de proyectos que están día a día implementando estudios técnicos con ellos, no obstante, manifiestan la necesidad de una distribución más equitativa de beneficios, tal como lo indica el Convenio 169.

Para fortalecer la consulta al pueblo indígena en los estudios de impacto ambiental, la consulta indígena debe ser contemplada desde las primeras etapas ampliando la visión ambientalizada; debe ser apoyado por una agencia estatal distinta al SEA, que tenga la capacidad técnica y organizacional de centralizar las consultas indígenas; y debe ser participativa en el diseño de un proyecto para llevar el conocimiento tradicional a la toma de decisiones ambientales.

Este trabajo pretende contribuir a iluminar el problema con nuestros pueblos originarios incorporándolos bajo la teoría de gobernanza ambiental, llamando la atención de nuestros legisladores sobre la legitimidad de los conocimientos indígenas y el derecho inherente a la autodeterminación. Finalmente, el análisis realizado en la presente investigación apunta a contribuir a la reflexión en cómo se ha planificado la inclusión de los pueblos indígenas en el desarrollo del país, pretendiendo que se tomen en cuenta estos antecedentes no sólo para la realización de nuevas investigaciones, sino que también, en las políticas y prácticas llevadas a cabo desde las administraciones públicas y privadas que operan a distintas escalas de acción territorial.

\section{Referencias Bibliográficas}

Aguilar-Støen, M. (2015). Global forest conservation initiatives as spaces for participation in Colombia and Costa Rica. Geoforum, 61, 36-44. https://doi. org/10.1016/j.geoforum.2015.02.012

Aguilar-Støen, M., Toni, F., Hirsch, C. (2016). Forest governance in Latin America: strategies for implementing REDD. En F. de Castro, B. Hogenboom \& M. Baud (Eds.), Environmental Governance in Latin America (pp. 205-233). London: Palgrave Macmillan.

Barkin, D., Lemus, B. (2015). Soluciones locales para la justicia ambiental. En F. de Castro, Hogenboom, B. \& M. Baud (Eds.), Gobernanza ambiental en América Latina (pp. 297-329). Buenos Aires: CLACSO.

Bingham, L.B. (2009). Collaborative Governance: Emerging Practices and the incomplete legal framework for Public and stakeholder voice. Missouri Journal of Dispute Resolution, 2, 269-325.

Bingham, L.B. (2011). Collaborative Governance. En M. Bevir (Ed.), The SAGE Handbook of Governance (pp. 386-401). London: SAGE Publications Ltd.

Bridge, D. \& Perreault, T. (2009). Environmental Governance. En N. Castree, D. Demeritt, D. Liverman \& B. Rhoads (Eds.), A Companion to Environmental Geography (pp. 475-497). Singapore: Blackwell Publishing.

Cleary, E. (2007). Chile: entre la imagen de éxito y los fantasmas del subdesarrollo. Polis, 18, 1-40.

Comisión Nacional de Medio Ambiente [CONAMA]. (1994). Manual de Evaluación de Impacto Ambiental: Conceptos y antecedentes básicos. Santiago, Chile. Recuperado de http://bibliotecadigital.ciren.cl/ handle/123456789/18824

Corporación Nacional de Desarrollo Indígena (CONADI). (2019). Respuesta a solicitud Folio AI002T0005064 a Oficina de Información y Acceso a Información Pública (Carta 08:346/19). Iquique, Chile. 
Cordero, L. (11 de noviembre de 2011). ¿Por qué la Corte Suprema se enverdeció?. El Mercurio. Recuperado de http://www.elmercurio.com/Legal/Noticias/AnalisisJuridico/2011/11/11/Por-que-la-Corte-Suprema-seenverdecio.aspx

Cordero, L. (2012). Corte Suprema y Medio Ambiente ¿Por qué la corte está revolucionando la regulación ambiental? Anuario de Derecho Público, 359-375.

Corvalán, C. (2015). La implementación de la consulta del convenio 169 de la OIT en Chile: las implicancias para la gran minería (Tesis de Magíster). Universidad de Chile. Santiago, Chile.

de Castro, F., Hogenboom, B., \& Baud, M. (2015). Gobernanza ambiental en América Latina. Buenos Aires: CLACSO.

Donoso, S. (2013). Declaraciones de impacto ambiental y consulta indígena en el SEIA: Comentario a la tendencia de homologación de los impactos ambientales que exigen un EIA y la susceptibilidad de afectación directa del Convenio 169 OIT. Sentencias Destacadas, 57-83. Recuperado de https:// lyd.org/wp-content/uploads/2016/12/pp-57-83Declaraciones-de-impacto-ambiental-y-consultasindigenas-en-el-SEIA-impacto-a-la-tendencia-dehomologacion-SDonoso.pdf

Donoso, S. (2014). Empresas y comunidades indigenas: el nuevo escenario que plantea el Convenio 169 de la OIT. Centro de Políticas Públicas UC, 73, 1-20. Recuperado de https://politicaspublicas. uc.cl/wp-content/uploads/2015/02/empresas-ycomunidades-indigenas.pdf

Donoso, S., Palacios, C. (2018). Pueblos indígenas y reconocimiento constitucional: aportes para un debate. Centro de Políticas Públicas UC, 103, 1-20. Recuperado de https://politicaspublicas. uc.cl/wp-content/uploads/2018/03/PDF-Temas103-Indigenas.pdf

Ellis S. (2005). Meaningful Consideration? A Review of Traditional Knowledge in Environmental Decision Making. Arctic, 58(1), 66-77. https://doi. org/10.14430/arctic390

e-SEIA. (1992-2019). Servicio de Evaluación Ambiental: búsqueda de proyectos. Santiago: Gobierno de Chile. Recuperado de http://seia.sea.gob.cl/busqueda/ buscarProyecto.php
FIMA. (1998-2016). Con derecho al ambiente: Corte Suprema. Santiago: FIMA. Recuperado de http:// www.fima.cl/?s=corte+suprema

Folchi M. (2001). Conflictos de contenido ambiental y ecologismo de los pobres: no siempre pobres, ni siempre ecologistas. Ecología Política, 22, 79-100.

Gómez Muñoz, M. (2003). Saber indígena y medioambiente: experiencias de aprendizaje comunitario. En E. Leff (Ed.), La complejidad ambiental (pp. 253-291). Buenos Aires: Siglo XXI ediciones.

Gleisner, C., Montt, S. (2014). COLLA. Serie introducción histórica y relatos de los pueblos originarios de Chile. Santiago, Chile. Recuperado de http:// bibliotecadigital.ciren.cl/handle/123456789/26185

Huencho, V. F. (2016). El proceso de formulación de políticas públicas indígenas en Chile: El caso del gobierno de Patricio Aylwin (1990-1994). Latin American Research Review, 51(2), 107-127. https:// doi.org/10.1353/lar.2016.0029

Instituto Nacional de Derechos Humanos (INDH). 2014. Informe en Derecho: El deber de consulta previa, libre e informada a los pueblos indígenas. Minuta aprobada por el Consejo del Instituto Nacional de Derechos Humanos el 28 de abril de 2014 - Sesión 201. Recuperado de http://bibliotecadigital.indh.cl/ handle/123456789/664

Jessop, B. (1998). The rise of governance and the risks of failure: the case of economic development. International Social Science Journal, 50(155), 29-45. https://doi.org/10.1111/1468-2451.00107

Kooiman, J. (2004). Gobernar en Gobernanza. Revista instituciones y Desarrollo, 16, 171-194.

Leff, E. (2003). Pensar la complejidad ambiental. En E. Leff (Ed.), La complejidad ambiental (pp. 7-53). Buenos Aires: Siglo XXI ediciones.

Leppe, J.P. (2015). Consulta indígena y procedimiento de evaluación de impacto ambiental Análisis de una relación normativa. Revista de Derecho (Valparaíso), 44, 369-384. https://doi.org/10.4067/s071868512015000100011 
Mayntz, R. (1998). Nuevos desafíos de governance. Traducción: "New Challenges to governance theory". Jean Monet Chair Paper RSC, 98-50.

Ministerio de Planificación y Cooperación. (1993). Ley $N^{\circ}$ 19.253: Sobre protección, fomento y desarrollo de los indígenas, y crea la Corporación Nacional de Desarrollo Indígena. Diario oficial de la República de Chile. Recuperado de https://www.leychile.cl/ Navegar?idNorma $=30620$

Ministerio del Medio Ambiente [MMA]. (2016). Informe Final: Comisión asesora presidencial para la evaluación del SEIA. Santiago de Chile. Recuperado de https://www.sea.gob.cl/sites/default/files/imce/ archivos/2017/05/10/35877_informe-mmaf_final.pdf

Ministerio Secretaría General de la Presidencia [MINSEGPRES]. (2010). Aprueba ley sobre bases generales del medio ambiente, Ley 19.300 (Modificada por Ley 20.417 MINSEGPRES, 2010). Diario oficial de la República de Chile. Recuperado de https:/www.leychile.cl/Navegar?idNorma=30667

Ministerio Secretaría General de la Presidencia [MINSEGPRES]. (2012). Ley que crea el Ministerio, el Servicio de Evaluación ambiental y la Superintendencia de Medio Ambiente (Ley $\mathrm{N}^{\circ}$. 20.417). Diario oficial de la República de Chile. Recuperado de https://www.leychile.cl/ Navegar?idNorma=1010459

Molina, F. (2012). Competing rationalities in water conflict: Mining and the indigenous community in Chiu Chiu, El Loa Province, northern Chile. Singapore Journal of Tropical Geography, 33(1), 93-107. https://doi.org/10.1111/j.1467-9493.2012.00451.x

Molina, R. (2014). Marcas memorables en los relatos Collas de Atacama. Chungara, 46 (4), 669-680. https://doi.org/10.4067/s0717-73562014000400009

Moore, ML, von der Porten, S., \& Castleden, H. (2017). Consultation is not consent: hydraulic fracturing and water governance on Indigenous lands in Canada. WIREs Water, 4(1), 1-15. https://doi.org/10.1002/ wat2.1180

Organización de Naciones Unidas [ONU]. (2007). Declaración de las Naciones Unidas sobre los derechos de los pueblos indígenas. Recuperado de http://www.un.org/esa/socdev/unpfii/documents/ DRIPS_es.pdf

Organización Internacional del Trabajo [OIT]. (1989.). Convenio $N^{\circ} 169$ Sobre pueblos indígenas y tribales en países independientes. Recuperado de http://http:// www.ilo.org/wcmsp5/groups/public/@ed_norm/@ normes/documents/publication/wcms_100910.pdf

OIT. (2006). Convenio $N^{\circ} 169$ Sobre pueblos indigenas $y$ tribales en países independientes. Santiago, Chile. Recuperado de https://www.leychile.cl/ Navegar?idNorma=279441

OIT. (2009). Los derechos de los pueblos indígenas y tribales en la práctica. Una guía sobre el Convenio núm. 169 de la OIT Recuperado de http://www.ilo. org/wcmsp5/groups/public/---dgreports/---dcomm/--publ/documents/publication/wcms_126163.pdf

OIT. (2016). Reporte Regional: Colombia, Costa Rica, Guatemala, Chile. Sobre el Convenio núm. 169 de la OIT sobre Pueblos Indigenas y Tribales en Países Independientes y la consulta previa a los pueblos indigenas en proyectos de inversión. Recuperado de http:/www.ilo.org/wcmsp5/groups/ public/---americas/---ro-lima/documents/publication/ wcms_507556.pdf

Pairican, F. (julio 2017). A 20 años de Lumaco: una ruptura histórica. Le Monde diplomatique, pp. 4-5. Recuperado de https://www.lemondediplomatique. cl/A-20-anos-de-Lumaco-Una-ruptura.html

Palomino-Schalscha, M. (2015). Ejercitando el poder en tiempos neoliberales: resistencia, comodificación y emprendimientos en Alto Biobío. En B. Bustos, M. Prieto y J. Barton (Eds.), Ecología Politica en Chile: Naturaleza, propiedad, conocimiento y poder (pp. 213-235). Santiago de Chile: Editorial Universitaria.

Pereira, M., Ulloa, A., O'ryan, R., \& De Miguel, C. (2009). Síndrome holandés, regalías mineras $y$ políticas de gobierno para un país dependiente de recursos naturales: el cobre en Chile. Santiago de Chile: CEPAL - Serie Medio ambiente y desarrollo.

Peter, G.B., \& Pierre, J. (2005). ¿Por qué ahora el interés por la gobernanza? En A. Cerrillo Martínez (Ed.), 
La gobernanza hoy: 10 textos de referencia (pp. $37-$ 54). Madrid: Instituto Nacional de Administración Pública (Inap).

Prats Català, J. (2005). Modos de gobernación de las sociedades globales. En A. Cerrillo Martínez. La gobernanza hoy: 10 textos de referencia (pp. $145-$ 172). Madrid: Instituto Nacional de Administración Pública (Inap).

Price Waterhouse Coopers (PWC). (2014). Judicialización de proyectos y conflictos indígenas: ¿Cómo evitarlos? Recuperado de http://www.acera.cl/wp-content/uploads/2014/03/ Judicializaci\%C3\%B3n-de-Proyectos-y-ConflictosInd $\%$ C $3 \%$ ADgenas-V $5 . p d f$

Quilaleo, F. (2018). La implementación del convenio 169 de la OIT en Chile: la paradoja de los derechos indígenas. Anuario de Derechos Humanos (14), 141153. https://doi.org/10.5354/0718-2279.2018.49199

Rehner, J., \& Vergara, F. (2014). Efectos recientes de la actividad exportadora sobre la reestructuración económica urbana en Chile. Revista de Geografía Norte Grande, 59, 83-103. https://doi.org/10.4067/ s0718-34022014000300006

Rhodes, R.A.W.(1996). The New Governance: Governing without Government. Political Studies, 44(4), 652-667. https://doi.org/10.1111/j.1467-9248.1996.tb01747.x

Ríos, A., \& Canessa, M. (2014). Propuesta metodológica para medir el índice de conflictividad de un territorio, un análisis de los riesgos sociales para proyectos de inversión. Rumbos TS, 9, 130-139.

Rivera, C. (2017). Del reconocimiento del territorio a la entrega de tierras: brechas de implementación en el proceso de entrega de tierras a las comunidades indígenas Colla de la comuna de Copiapó. Espacio y Sociedad, 1, 78-91.

Servicio de Evaluación Ambiental [SEA]. (2016). Instructivo sobre el proceso de Consulta a Pueblos Indígenas en conformidad con el Convenio $N^{\circ} 169$ de la OIT en el Sistema de Evaluación de Impacto Ambiental. (OF. ORD. D.E: N¹61116). Santiago: SEA.

SEA. Respuesta a solicitud Folio AW004T0003322 a Oficina de Información y Atención ciudadana. Santiago de Chile, 2019.
Sociedad de Fomento Fabril [SOFOFA]. (2016). Catastro de proyectos de Inversión- Edición 2016. Santiago: Chile.

Stoker, G. (1998). Governance as theory: five propositions. International Social Science Journal, 50(155), 17-28. https://doi.org/10.1111/14682451.00106

Universidad de Concepción. (1993). Capítulo Cuarto: Los Collas de la Cordillera de Atacama. Recuperado de http://ww2.educarchile.cl/personas/indigena/gfx/ pueblo_colla.pdf

Walter, M. (2009). Conflictos ambientales, socioambientales, ecológicos distributivos, de contenido ambiental...Reflexionando sobre enfoques y definiciones. CIP-Ecosocial, 6, 1-9.

Walter, M., \& Urkidi, L. (2015). Consultas Comunitarias: respuestas a la minería a gran escala en América Latina. En F. de Castro, B. Hogenboom \& M. Baud (Eds.), Gobernanza ambiental en América Latina (pp. 331-370). Buenos Aires: CLACSO.

von der Porten, S., Löe, R., Plummer, R. (2015). Collaborative Environmental Governance and Indigenous Peoples: Recommendations for practice. Environmental Practice, 17, 134-144.

Zurbriggen, C. (2011). Gobernanza: una mirada desde América Latina. Perfiles Latinoamericanos 38, 39-63.

\section{Agradecimentos}

Investigación elaborada, gracias al apoyo de Cedrem consultores, en el marco de una Tesis para optar al grado M.Sc. Governance of Risk and Resources de la Universidad de Heildelberg. 